\title{
Equine pituitary pars intermedia dysfunction: current perspectives on diagnosis and management
}

This article was published in the following Dove Press journal:

Veterinary Medicine: Research and Reports

20 August 2015

Number of times this article has been viewed

\section{Caroline W Spelta}

Townsville Vet Clinic, Townsville, QLD, Australia
Correspondence: Caroline W Spelta Townsville Vet Clinic, 32-34 Anne St, Aitkenvale, QLD 48I4, Australia

Email caroline@townsvillevetclinic.com.au
Abstract: Equine pituitary pars intermedia dysfunction (PPID) is a neurodegenerative disease of the hypothalamus, resulting in the loss of dopaminergic inhibition of pars intermedia. An oxidative stress injury of unknown etiology has been suggested to initiate the neurodegeneration. While hypertrichosis (formerly known as hirsutism) is considered pathognomic for advanced disease, the antemortem diagnosis of subclinical and early disease has continued to prove difficult. Numerous tests have been used with varying sensitivities and specificities. The overnight dexamethasone suppression test, originally documented to have $100 \%$ sensitivity and specificity in horses with advanced disease, has proven to be less valuable in identifying early disease. Basal plasma adrenocorticotropin concentrations have improved sensitivity and specificity when sampled during the autumn months, and $\alpha$-melanocyte-stimulating hormone, while not yet commercially available, shows promise as a sensitive and specific single sample test. Recent advances in our knowledge include the strong association between laminitis and hyperinsulinemia, both common clinical signs associated with PPID. The pathogenesis of hyperinsulinemia, laminitis, and their association with this disease is a focus of current research. The dopamine agonist pergolide mesylate is still the mainstay of medical management, with studies on oral bioavailability, pharmacokinetics, and long-term survival rates now published.

Keywords: PPID, ACTH, $\alpha-\mathrm{MSH}$, laminitis, pergolide, hypertrichosis, pars pituitary intermedia dysfunction

\section{Introduction}

Equine Cushing's disease, now known as pituitary pars intermedia dysfunction (PPID), was first described in 1932. ${ }^{1}$ The classic clinical picture is one of advanced disease, the aging horse or pony with a persistent, long, curling hair coat; epaxial muscle wastage; pendulous abdomen; and an increased risk of laminitis. ${ }^{2}$ In recent epidemiological surveys, $21 \%-22 \%$ of aged horses and ponies had PPID based on endocrine testing, an increase in reported prevalence from previous studies..$^{3-6}$

Considerable research into the pathophysiology of PPID has occurred in recent years. The current pathophysiological theory for PPID is an age-related oxidative stress-induced neurodegeneration of the dopaminergic neurons of the hypothalamus. ${ }^{7-10}$ This in turn causes a loss of dopaminergic inhibition on the pars intermedia resulting in an increased production of pro-opiomelanocortin (POMC)-derived peptides including adrenocorticotropin (ACTH), $\alpha$-melanocyte-stimulating hormone ( $\alpha$-MSH), $\beta$-endorphin, and corticotrophin-like intermediate peptide. Of these hormones, the production and actions of ACTH and $\alpha$-MSH have been most closely studied and assessed for diagnostic test potential. The cause of the oxidative stress compared 
to age-matched controls is yet to be determined. The very slow progression of this disease makes the elucidation of an initiating cause or insult difficult as clinical signs are only evident after a substantial time lapse (years), when normal hormonal function is lost. ${ }^{11}$

In the normal pituitary, the pars distalis is responsible for the majority of ACTH production with small amounts of ACTH from melanocyte-derived POMC. ${ }^{9}$ The pars intermedia's primary product is $\alpha-\mathrm{MSH}$, a metabolically active peptide involved in metabolism and obesity, which has potent anti-inflammatory properties. The cortiotrophs in the pars distalis are under a glucocorticoid negative feedback loop. The production and secretion of the POMC peptides from the melanotropes in the pars intermedia are under dopamine inhibitory control from the hypothalamus. Hypothalamus and pituitary activities are influenced by season and photoperiod length, with significant up-regulation of $\alpha-\mathrm{MSH}$ and ACTH production in the late summer and autumn months (periods of decreasing day length). ${ }^{12-14}$ The increased activity is seen in both unaffected and PPID-affected horses and ponies. This has a significant effect on basal endogenous ACTH and $\alpha-\mathrm{MSH}$ levels and therefore on diagnostic testing during this period.

In 1994, Dybdal et al described the overnight dexamethasone suppression test (ODST) as a $100 \%$ sensitive and specific diagnostic test based on a population of horses with clinically advanced PPID. ${ }^{2}$ The challenge since then has been the diagnosis of PPID in subclinical and early clinical horses and ponies. Plasma POMC peptide levels are secreted along a concentration continuum. Horses and ponies will have normal to mildly elevated levels early in the disease process. There is a transition period or "gray zone" within this continuum, where hormone levels may be normal in clinically suggestive cases or elevated in clinically normal horses and ponies. ${ }^{15}$ Clinically overt cases will have significantly increased plasma POMC concentrations than either clinically normal or early clinical cases. Cutoff levels for the current diagnostic tests are based on statistical methodology to maximize sensitivity and specificity. To minimize the number of false negative and positive results, a number of recommendations by various equine endocrinology groups have been made including the use of seasonally adjusted reference ranges and further dynamic testing. ${ }^{16-18}$

\section{Diagnostics}

Diagnosis of PPID has included the presence of overt clinical signs, endogenous hormone levels including ACTH, insulin and cortisol levels, dynamic endocrine testing such as the
ODST, thyrotropin-releasing hormone (TRH) stimulation test measuring cortisol or ACTH, combined TRH-dexamethasone suppression test, domperidone stimulation test, and histology. ${ }^{2,19-23}$ Most recently, $\alpha-\mathrm{MSH}$ has also been evaluated as a possible diagnostic option. ${ }^{24}$ Of these tests, the current recommendations are the use of endogenous plasma ACTH with seasonally adjusted reference ranges in combination with suggestive clinical signs. Horses and ponies with ambiguous results (suggestive clinical signs with normal ACTH results) or in the gray zone (clinically normal horses with mildly elevated ACTH levels) should either be resampled during autumn or undergo a TRH stimulation test measuring ACTH to improve sensitivity.

\section{Clinical signs}

A long, wavy, or curling hair coat, known as hirsutism, has long been considered pathognomonic for advanced PPID disease. The long hair coat in horses with advanced PPID has recently been determined to be due to the persistence of hair follicles in the anagen stage and is therefore more correctly termed "hypertrichosis". ${ }^{25}$ Follicles arrested in the anagen stage fail to shed, as occuring in PPID-affected horses and ponies. Hirsutism, the term commonly used to describe the hair coat changes in PPID-affected horses and ponies, has been borrowed from the medical field and refers to the excessive androgen-dependent growth of hair in women with Cushing's disease. The term "hirsutism", therefore, has been incorrectly used to describe the hair coat abnormalities seen in PPID.

Laminitis is commonly associated with PPID. ${ }^{1,9,22,26}$ In all, $13 \%$ of PPID confirmed horses had a history of or concurrent laminitis in a recent survey. ${ }^{3}$ Historically, it was thought that the loss of the diurnal cortisol fluctuations with exposure to increased daily cortisol levels was responsible for the PPIDassociated laminitis. ${ }^{27,28}$ Recent work on the pathogenesis of endocrinopathic laminitis, however, has demonstrated a strong association with a concurrent hyperinsulinemia. ${ }^{29-31}$ The exact mechanisms of this association and the association between hyperinsulinemia and PPID are currently unknown and are the subject of ongoing research.

Other common clinical signs include bulging supraorbital fat pads, lethargy or docility, epaxial muscle wastage, a pendulous abdomen, sweating abnormalities, polyuria/ polydipsia, poor wound healing, chronic infections or increased susceptibility to infection, endoparasitism, and very rarely, seizure-like activity. 1,9,22,32-34 The presence of three or more common clinical signs (hypertrichosis, wasted epaxial muscles, pendulous abdomen, bulging supraorbital fat pads, 
and divergent laminar rings) in combination with a seasonally adjusted endogenous ACTH value has recently been documented to be the "clinically diagnostic gold standard".

\section{Plasma ACTH}

In the hypothalamus-pituitary-adrenal axis, ACTH secretion from the pituitary stimulates the adrenal glands to increase the secretion of cortisol. In PPID-affected horses and ponies, only $20 \%$ have adrenomegaly, supporting the theory that the excessive ACTH produced in PPID-affected horses and ponies is biologically inert, resulting in $\mathrm{ACTH}-$ cortisol dissociation. ${ }^{9,35}$ ACTH secretion is affected by numerous external factors including stress, transport, illness, marked pain, and debilitation and exercise. ${ }^{36-39} \mathrm{ACTH}$ secretion is also affected by day length, with increased secretion associated with decreasing photoperiods during the late summer and autumn (Table 1) ${ }^{40}$ This effect does not appear to be universal though, with varying degrees of seasonal fluctuations documented at different latitudes. ${ }^{15,41-44}$ PPID-affected horses and ponies still show the greatest elevations. Increased plasma ACTH secretion in the autumn months in both normal and PPID-affected horses and ponies initially resulted in reluctance to measure endogenous plasma ACTH due to a presumed decrease in specificity during these months. However, recent work and determination of seasonally adjusted ACTH reference ranges has significantly increased the sensitivity and specificity of endogenous plasma ACTH levels during this period. The seasonally adjusted values are latitude dependent. Large, multicenter collaborations to establish regional seasonally adjusted values are needed. In lieu of these data, using a local laboratory with its own established reference ranges is recommended.
Even with the determination of seasonal variation and adjusted cutoff values, there still exists a transitional or "gray" zone.$^{45}$ Horses and ponies that have endogenous plasma ACTH value of between 29 and $40 \mathrm{pg} / \mathrm{mL}$ (northern hemisphere non-autumn reference range) during the winter, spring, and summer months with no or few subtle clinical signs present a clinical dilemma and should be retested during the autumn when the test has greater sensitivity and specificity, decreasing the likelihood of false positive results. ${ }^{46}$ Alternatively, a TRH stimulation test measuring ACTH, instead of cortisol, can be performed (see TRH stimulation test measuring $\mathrm{ACTH})$.

Ultradian and circadian rhythms and effects of feeding have been investigated to optimize sample timing. No ultradian rhythms were found in neither unaffected or PPIDaffected horses and ponies ${ }^{45}$ Further to this, paired sampling was not found to increase sensitivity and specificity ${ }^{47}$ Rendle et al identified a circadian rhythm in unaffected horses and ponies with plasma ACTH values highest at 8 am and decreasing throughout the day, whereas Diez de Castro et al did not demonstrate a circadian rhythm in healthy horses. ${ }^{45,48}$ A significant postprandial increase in endogenous ACTH has been documented, suggesting that the feeding status of the animal may also be a cofounder for both endogenous and dynamic ACTH testing. ${ }^{48}$

Sample handling and storage of plasma for endogenous ACTH measurement has also been investigated. Contrary to previous recommendations, while there is a decrease in endogenous ACTH levels over time, clinically relevant results can be obtained from chilled, non-centrifuged plasma processed within 48 hours of collection. ${ }^{9,49}$ Samples held for greater than 48 hours prior to processing should be centrifuged, the plasma separated and frozen while awaiting

Table I ACTH upper reference ranges, sensitivity, and specificity data from different locations and seasons

\begin{tabular}{|c|c|c|c|c|}
\hline \multirow[t]{2}{*}{ Location/latitude } & \multicolumn{3}{|c|}{$\begin{array}{l}\text { Subtropics } \\
\text { Southern hemisphere }\left(-27^{\circ} 24^{\prime} \text { to }-24^{\circ} 54^{\prime}\right)^{15}\end{array}$} & \multirow{2}{*}{$\begin{array}{l}\text { Temperate Northern } \\
\text { hemisphere }{ }^{\mathrm{a}, 44,46} \\
\text { Cutoff } \\
\end{array}$} \\
\hline & Sn (\%) & Sp (\%) & Cutoff & \\
\hline \multicolumn{5}{|l|}{$\overline{\mathrm{ACTH}}$} \\
\hline Autumn & 100 & 95 & $77.4 \mathrm{pg} / \mathrm{mL}$ & \\
\hline Winter-summer & 80 & 82 & $29.7 \mathrm{pg} / \mathrm{mL}$ & \\
\hline Late summer to mid-autumn & & & & $47 \mathrm{pg} / \mathrm{mL}$ \\
\hline Late autumn to mid-summer & & & & $29 \mathrm{pg} / \mathrm{mL}$ \\
\hline \multicolumn{5}{|l|}{$\alpha-M S H$} \\
\hline Autumn & 100 & 97 & $165.4 \mathrm{pmol} / \mathrm{L}$ & \\
\hline Winter-summer & 59 & 93 & $52 \mathrm{pmol} / \mathrm{L}$ & \\
\hline Late summer to mid-autumn & & & & No precise value documented \\
\hline Late autumn to mid-summer & & & & $35 \mathrm{pmol} / \mathrm{L}$ \\
\hline
\end{tabular}

Note: a Northern hemisphere reference ranges have been calculated on normal distributions and $95 \%$ confidence intervals, with no sensitivity or specificity data to date.

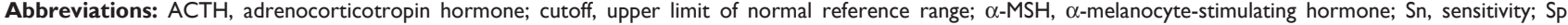
specificity. 
transport to the laboratory. The inclusion of the preservative $\mathrm{N}$-phenylmaleimide had no effect on plasma ACTH levels over time. $^{49}$

\section{TRH stimulation test measuring $\mathrm{ACTH}$}

The TRH stimulation test originally measured cortisol levels 10 and 30 minutes post-TRH administration and had a sensitivity of $92 \%$. Specificity, positive and negative predicative values were improved when combined with the dexamethasone suppression test. ${ }^{19}$ In horses and ponies with PPID though, cortisol levels are rarely elevated in the face of significant elevations in ACTH, suggesting that the melanotropic-derived ACTH is immunologically active but biologically inert and, therefore, dissociated from serum cortisol levels. ${ }^{9,35}$ This observation has led to endogenous ACTH being measured 10 and 30 minutes post-TRH administration (Table 2), resulting in sensitivity of $94 \%$ and specificity of $78 \%$ at 30 minutes using a cutoff of $36 \mathrm{pg} / \mathrm{mL} .{ }^{35}$ In this study, plasma ACTH was shown to be superior than serum cortisol for the diagnosis of PPID.

As with endogenous plasma ACTH, the TRH stimulation test is affected by season and seasonally adjusted reference ranges are needed to improve specificity. Factors that confound the evaluation of endogenous ACTH results will impact on the TRH stimulation test as well. TRH has been both expensive and difficult to obtain and is therefore a test usually performed at referral and university institutions.
A compounded TRH product stored at room temperature has been assessed and found to give comparable test results. The availability and cost of this product outside North America is unknown at this time. ${ }^{50}$

\section{Overnight dexamethasone suppression}

\section{test}

The ODST has, for many decades, been considered the "gold standard" antemortem diagnostic test. This was based on a sensitivity and specificity of $100 \%$ achieved in a population of horses and ponies with advanced PPID. ${ }^{2}$ The sensitivity and specificity in early and subclinical disease are $65 \%$ and $76 \%$, respectively. ${ }^{19}$ The potential induction or exacerbation of existing laminitis post-ODST and the requirement of either two visits or overnight hospitalization of the patient have limited the practicality of this test. ${ }^{1}$ As a downstream product of the hypothalamus-pituitary-adrenal axis, cortisol secretion is also seasonally affected. To date, there have been no seasonally adjusted reference ranges documented for the ODST.

\section{$\alpha$-Melanocyte-stimulating hormone}

$\alpha-\mathrm{MSH}$ is primarily derived from the pars intermedia and undergoes increased secretion occurring in the later summer and autumn months (Table 1 ). ${ }^{14}$ Its role in metabolism and increased secretion during periods of decreasing day length is a proposed survival mechanism to increase fat

Table 2 PPID test protocols

\begin{tabular}{|c|c|c|}
\hline Test & Protocol & Sample type required \\
\hline $\mathrm{ACTH}$ & $\begin{array}{l}\text { - Blood collected in plastic EDTA vacutainer } \\
\text { If } \leq 48 \text { hours to laboratory processing } \\
\text { - No further processing required } \\
\text { If } \geq 48 \text { hours until laboratory processing } \\
\text { - Centrifuge sample } \\
\text { - Separate plasma and place in a plain (red top) plastic vacutainer, marked EDTA Plasma } \\
\text { - Freeze plasma and send on ice to laboratory }\end{array}$ & Plasma (EDTA) \\
\hline $\begin{array}{l}\text { TRH stimulation test } \\
\text { measuring } A C T H\end{array}$ & $\begin{array}{l}\text { - Collect blood in plastic EDTA (purple top) tube } \\
\text { - Administer } 1.0 \mathrm{mg} \text { (total dose) TRH intravenously } \\
\text { - Collect blood in plasma EDTA (purple top) tube } 30 \text { minutes later } \\
\text { - Submit samples for ACTH levels (Sample handling for ACTH is outlined above) }\end{array}$ & Plasma (EDTA) \\
\hline ODST & $\begin{array}{l}5 \mathrm{pm} \\
\text { - Collect blood in a plain (red top) vacutainer for basal cortisol level } \\
\text { - Administer } 40 \mu \mathrm{g} / \mathrm{kg} \text { of dexamethasone intramuscularly } \\
8 \mathrm{am}-12 \mathrm{pm} \text { hours the next day (7 pm-12 am later) } \\
\text { - Collect second blood sample in a plain (red top) vacutainer for second cortisol level }\end{array}$ & Serum $\times 2$ \\
\hline$\alpha-\mathrm{MSH}$ & - Blood collected in EDTA vacutainer & Plasma (EDTA) \\
\hline Insulin & - Collect blood in a plain (red top) vacutainer, preferably after a short overnight fast & Serum \\
\hline Oral glucose challenge & $\begin{array}{l}\text { - Give } 0.15 \mathrm{~mL} / \mathrm{kg} \text { of Karo Lyte corn syrup orally } \\
\text { - Collect blood in a plain (red top) vacutainer for an insulin level } 60-90 \text { minutes later }\end{array}$ & Serum \\
\hline
\end{tabular}

Abbreviations: ACTH, adrenocorticotropin hormone; EDTA, ethylenediaminetetraacetic acid; $\alpha$-MSH, $\alpha$-melanocyte-stimulating hormone; ODST, overnight dexamethasone suppression test; PPID, pituitary pars intermedia dysfunction; TRH, thyrotropin-releasing hormone. 
stores in preparation for anticipated feed restriction in harsh winters. This same mechanism may be responsible for the associated obesity and regional fat deposition seen in PPID cases. PPID-affected horses and ponies have a greater magnitude in plasma $\alpha$-MSH levels than concurrent ACTH levels, suggesting that $\alpha$-MSH may rise early in the disease process and, therefore, be a more sensitive diagnostic test. ${ }^{14}$ Plasma $\alpha-\mathrm{MSH}$ is stable in chilled, whole blood for up to 8 hours, but does require centrifugation, plasma separation, and freezing prior to transportation to the laboratory, unlike ACTH which, when chilled, is stable in whole blood for up to 48 hours. ${ }^{14,49} \alpha-\mathrm{MSH}$ is not effected by stress, illness, exercise, or transportation and as such has less confounders on result interpretation than $\mathrm{ACTH} .{ }^{14}$ In a recent epidemiological study, $\alpha$-MSH had a higher sensitivity and specificity than ACTH when tested in the autumn months. ${ }^{15}$ Currently, $\alpha$-MSH assays are not commercially available and only used in research facilities.

\section{Insulin}

Almost 90\% of laminitis diagnosed is classed as endocrinopathic in origin. ${ }^{51}$ The initial theorized pathogenesis of PPID-associated laminitis was glucocorticoid induced, due to exposure of the lamellar tissue to increased total daily cortisol as a result of the cortisol diurnal secretory rhythm loss; this has not been clearly demonstrated in studies though. ${ }^{27,28,52}$ Hyperinsulinemia has been repeatedly documented to cause laminitis in healthy non-laminitic horses and may be the major mechanism associated with pasture-associated laminitis. ${ }^{29,53}$ PPID-affected horses and ponies with concurrent hyperinsulinemia experience laminitic episodes more frequently than normoinsulinemic PPID horses and ponies. ${ }^{31}$ The presence of PPID alone though does not impair insulin sensitivity. ${ }^{54}$ Insulin sensitivity decreases with increasing age in equids. ${ }^{55,56}$ The mechanism by which hyperinsulinemia induces laminitis and whether it is the same mechanism/s associated with PPID or a concurrent disease is yet to be elucidated.

Basal serum insulin concentrations or dynamic insulin testing should be undertaken in horses and ponies with PPID and laminitis. The presence of a concurrent hyperinsulinemia will influence the management and feeding practices implemented. To standardize testing, samples for basal serum insulin should be taken in the morning after an overnight fast. A small biscuit of good quality given and consumed before $10 \mathrm{pm}$ is allowed. Insulin levels greater than $20 \mathrm{IU} / \mathrm{L}$ are considered hyperinsulinemic. ${ }^{57}$ Dynamic testing has the added benefit of assessing postprandial insulin levels (the pancreatic $\beta$-cells response to a glucose challenge).
Dynamic testing involves the oral administration of 0.15 $\mathrm{mL} / \mathrm{kg}$ of corn syrup (ACH Food Companies, Karo Lyte, Cordova, TN, USA) orally after a short overnight fast (ie, a small biscuit of hay given, consumed, and any remainder removed before $10 \mathrm{pm}$ the night before), and serum insulin samples taken 60 and 90 minutes later. Serum insulin of less than $45 \mathrm{IU} / \mathrm{L}$ at both time points is found in healthy horses. Serum insulin levels between 45 and 60 IU/L are equivocal and greater than $60 \mathrm{IU} / \mathrm{L}$ is evidence of postprandial hyperinsulinemia and insulin dysregulation. ${ }^{58}$ Alternatively, $1 \mathrm{~g} / \mathrm{kg}$ of dextrose powder can be fed in a small meal of chaff or low-sugar chopped feed and mixed in water after a short overnight fast. Serum insulin levels are measured $60 \mathrm{~min}-$ utes later. Insulin levels greater than $85 \mathrm{IU} / \mathrm{L}$ are considered diagnostic for hyperinsulinemia. ${ }^{59}$ Other tests include the combined insulin and glucose test and the insulin tolerance test. Neither of these tests assesses both the pancreatic secretion and clearance of insulin. They also require more time and sampling with more confounders when compared with the oral glucose tests. ${ }^{60}$

\section{Histopathology}

For many other diseases, confirmation of a previously described histopathological appearance is considered the gold standard to which all antemortem tests are compared. Confirmation of the disease on histopathology is therefore used to calculate the sensitivity and specificity of a given antemortem test. This test standard has been unreliable in PPID, with documented inconsistencies between pathologists on classification of histological changes and therefore final diagnosis. ${ }^{23}$ The pituitary architecture and size is also subject to seasonal variation. ${ }^{61}$ The current accepted description is a hyperplastic pars intermedia with a singular large or multiple small adenomas. ${ }^{9}$

\section{Treatment}

There is currently no cure for PPID. Pergolide mesylate, an ergot-derived D2-dopamine agonist, is still the drug of choice for the medical management of PPID. ${ }^{9}$ The replacement of dopamine and reestablishment of dopamine inhibition on the POMC-derived peptides results in normalization of pituitary hormone levels and resolution of clinical signs.

\section{Management}

PPID-affected horses and ponies require excellent husbandry and management practices. The presence of insulin dysregulation and postprandial hyperinsulinemia requires careful dietary management. ${ }^{62}$ Horses and ponies with a 
history of laminitis or documented hyperinsulinemia require restricted access to diets high in soluble nonstructural carbohydrates, including lush or fast-growing pastures and sweet feeds to decrease the frequency of laminitic episodes.$^{63}$ The use of a grazing muzzle aids in dietary restriction without restricting exercise. Grazing should be restricted from mid-morning to late afternoon, as wilting increases the sugar content in the pasture. Likewise, grazing should be restricted after a harsh frost as this also increases the sugar content of pasture. Soaking hay for 60 minutes in cold water will also decrease the sugar content. All PPID-affected horses and ponies benefit from the feeding of good quality senior diets to provide adequate protein intake to minimize muscle catabolism.

PPID-affected horses and ponies are more likely to suffer from moderate to severe endoparasitism compared with age-matched controls. ${ }^{33}$ PPID horses and ponies tend to be the "high egg shedders" in the herd and have a shorter egg reemergence period post-worming than their herd mates. A deworming program which incorporates regular fecal egg counts and fecal egg reduction test is optimal.

Regular dental checks and vaccinations are recommended. PPID horses and ponies, while having an increased susceptibility to infections, continue to have adequate immune responses to vaccination..$^{64,65}$ The degree of response and duration of immunity may vary depending on severity of disease compared with age-matched controls. Further research is required to further quantify these changes and assess whether a change in vaccination dosage frequency should be recommended. Early and aggressive medical management of infections is also needed.

\section{Pergolide mesylate}

Pergolide mesylate is available in Australia and New Zealand as a liquid (Ranvet Pty Ltd, Ranvet's Pergolide, East Botany NSW, Australia) and as a tablet (Boehringer Ingelheim, Prascend, Ingelheim am Rhein, Rhineland-Palatinate, Germany). Only the tablet form is commercially available in the UK, Europe, and North America. The $200 \mathrm{mg} / \mathrm{mL}$ liquid formulation allows for very accurate dosing. Pergolide, however, is unstable and light sensitive in the liquid form, with a short 3-month shelf life, potentially resulting in drug wastage and extra cost to the client. The tablet formulation is more stable with a shelf life of up to 24 months. The $1 \mathrm{mg}$ tablets are half-scored allowing for one division and a dosage accuracy of $0.5 \mathrm{mg}$. Compounded pergolide mesylate has shown itself to be unreliable in both drug distribution and stability and is not recommended for use. ${ }^{66}$
The current recommended dose rate is $0.002 \mathrm{mg} / \mathrm{kg}$ once daily orally. ${ }^{9}$ Lower doses have been successfully used. ${ }^{34,67}$ Once clinical and biochemical resolution has been achieved, the dose should be titrated down to the lowest effective dose to prevent side effects such as anorexia, sweating, colic, diarrhea, and neurological signs. ${ }^{68}$ These side effects are most commonly seen at higher dose rates $(0.01 \mathrm{mg} / \mathrm{kg})$ and can be avoided by starting at a lower dose rate and gradually increasing the dose if needed over a period of weeks. Dosage efficacy is based on the demonstration of normalized plasma ACTH levels and the resolution of clinical signs. It should be noted that hair coat shedding will not be seen until the spring, regardless of appropriate dosage administration, due to the day length effect on $\alpha-\mathrm{MSH}$.

The serotonin antagonist cyproheptadine is no longer considered useful either alone or in conjunction with pergolide due to the lack of efficacy achieved above that attributed to either management or pergolide. ${ }^{68}$

\section{Conclusion}

The last 3 decades has seen considerable expansion in our knowledge of PPID. There is still much to learn though. A "gold-standard" antemortem diagnostic test continues to be elusive. Currently, basal plasma ACTH is the most sensitive and specific test commercially available for early diagnosis. The sensitivity and specificity increase if sampling occurs during the autumn months. Dynamic testing using the TRH stimulation test measuring ACTH is also useful in detecting early clinical disease. $\alpha-\mathrm{MSH}$ shows promise as a single sample diagnostic test, but is not yet commercially available. Pergolide is still the drug of choice for medical management of clinical signs and, when used in conjunction with improved husbandry and management practices, can significantly improve the quality and duration of life of PPID horses and ponies for many years.

\section{Disclosure}

The author reports no conflicts of interest in this work.

\section{References}

1. Schott H II. Pituitary pars intermedia dysfunction: equine Cushing's disease. Vet Clin North Am Equine Pract. 2002;18(2):237-270.

2. Dybdal NO, Hargreaves KM, Madigan JE, Gribble DH, Kennedy PC, Stabenfeldt GH. Diagnostic testing for pituitary pars intermedia dysfunction in horses. J Am Vet Med Assoc. 1994;204(4):627-632.

3. McGowan TW, Pinchbeck GP, McGowan CM. Prevalence, risk factors and clinical signs predictive for equine pituitary pars intermedia dysfunction in aged horses. Equine Vet J. 2013;45(1):74-79.

4. Ireland JL, Clegg PD, McGowan CM, McKane SA, Chandler KJ, Pinchbeck GL. Disease prevalence in geriatric horses in the United Kingdom: veterinary clinical assessment of 200 cases. Equine Vet $J$. 2012;44(1):101-106. 
5. Brosnahan MM, Paradis MR. Demographic and clinical characteristics of geriatric horses: 467 cases (1989-1999). J Am Vet Med Assoc. 2003; 223(1):93-98.

6. Mellor D, Love S, Walker R, Gettinby G, Reid S. Sentinel practice-based survey of the management and health of horses in Northern Britain. Vec Rec. 2001;149(14):417-423.

7. McFarlane D, Donaldson M, Saleh T, Cribb A. The role of dopaminergic neurodegeneration in equine pituitary pars intermedia dysfunction (equine Cushing's disease). Proceedings of the 49th Annual Connvention of the American Association of Equine Practitioners, New Orleans, LO, USA; 21-25 November 2003:233-237.

8. McFarlane D, Dybdal N, Donaldson MT, Miller L, Cribb AE. Nitration and increased $\alpha$-synuclein expression associated with dopaminergic neurodegeneration in equine pituitary pars intermedia dysfunction. J Neuroendocrinol. 2005;17(2):73-80.

9. McFarlane D. Equine pituitary pars intermedia dysfunction. Vet Clin North Am Equine Pract. 2011;27(1):93-113.

10. McFarlane D, Cribb AE. Systemic and pituitary pars intermedia antioxidant capacity associated with pars intermedia oxidative stress and dysfunction in horses. Am J Vet Res. 2005;66(12):2065-2072.

11. McFarlane D. Advantages and limitations of the equine disease, pituitary pars intermedia dysfunction as a model of spontaneous dopaminergic neurodegenerative disease. Ageing Res Rev. 2007;6(1):54-63.

12. Beech J, Boston RC, McFarlane D, Lindborg S. Evaluation of plasma acth, $\alpha$-melanocyte-stimulating hormone, and insulin concentrations during various photoperiods in clinically normal horses and ponies and those with pituitary pars intermedia dysfunction. J Am Vet Med Assoc. 2009;235(6):715-722.

13. Schreiber CM, Stewart AJ, Kwessi E, et al. Seasonal variation in results of diagnostic tests for pituitary pars intermedia dysfunction in older, clinically normal geldings. J Am Vet Med Assoc. 2012;241(2):241-248.

14. McFarlane D, Donaldson MT, McDonnell SM, Cribb AE. Effects of season and sample handling on measurement of plasma $\alpha$-melanocytestimulating hormone concentrations in horses and ponies. Am JVet Res. 2004;65(11):1463-1468.

15. Mc Gowan TW, Pinchbeck GP, McGowan CM. Evaluation of basal plasma $\alpha$-melanocyte-stimulating hormone and adrenocorticotrophic hormone concentrations for the diagnosis of pituitary pars intermedia dysfunction from a population of aged horses. Equine Vet J. 2013;45(1): 66-73.

16. Frank N, Andrews FM, Durham A, McFarlane D, Schott H. Recommendations for the diagnosis and treatment of PPID 2011. Available from: http://sites.tufts.edu/equineendogroup/. Accessed May 11, 2015.

17. Durham AE, McGowan CM, Fey K, Tamzali Y, van der Kolk JH. Pituitary pars intermedia dysfunction: Diagnosis and treatment. Equine Vet Ed. 2014;26:216-223.

18. Tan R HH, Spelta CW, Sonis JM, et al. Key recommendations form leading Australian and New Zealand equine specialists for the diagnosis and treatment of PPID (equine Cushing's disesase); 2014. Available from: http://www.talkaboutlaminitis.com.au/vet-area/downloads. Accessed May 11, 2015.

19. Frank N, Andrews FM, Sommardahl CS, Eiler H, Rohrbach BW, Donnell RL. Evaluation of the combined dexamethasone suppression/ thyrotropin-releasing hormone stimulation test for detection of pars intermedia pituitary adenomas in horses. JVet Intern Med. 2006;20(4): 987-993.

20. Sojka JE, Jackson LP, Moore G, Miller M. Domperidone causes an increase in endogenous acth concentration in horses with pituitary pars intermedia dysfunction (equine Cushing's disease). Proceedings of the 52nd Annual Convention of the American Association of Equine Practitioners; San Antonio, 2006.

21. Couëtil L, Paradis MR, Knoll J. Plasma adrenocorticotropin concentration in healthy horses and in horses with clinical signs of hyperadrenocorticism. J Vet Intern Med. 1996;10(1):1-6.

22. Love S. Equine Cushing's disease. Vet J. 1993;149(2):139-153.
23. McFarlane D, Miller LM, Craig LE, et al. Agreement in histologic assessments of the pituitary pars intermedia in aged horses. Am J Vet Res. 2005;66(12):2055-2059.

24. McFarlane D, Beech J, Cribb A. Alpha-melanocyte stimulating hormone release in response to thyrotropin releasing hormone in healthy horses, horses with pituitary pars intermedia dysfunction and equine pars intermedia explants. Domest Anim Endocrinol. 2006;30(4): 276-288.

25. Innerå M, Petersen AD, Desjardins DR, Steficek BA, Rosser EJ Jr, Schott HC 2nd. Comparison of hair follicle histology between horses with pituitary pars intermedia dysfunction and excessive hair growth and normal aged horses. Vet Dermatol. 2013;24(1):212-217.

26. Van der Kolk J, Kalsbeek H, Van Garderen E, Wensing T, Breukink H. Equine pituitary neoplasia: a clinical report of 21 cases (1990-1992). Vec Rec. 1993;133(24):594.

27. Johnson PJ, Slight SH, Ganjam VK, Kreeger JM. Glucocorticoids and laminitis in the horse. Vet Clin North Am Equine Pract. 2002;18(2): 219-236.

28. Johnson PJ, Messer NT, Slight SH, Wiedmeyer C, Buff P, Ganjam VK. Endocrinopathic laminitis in the horse. Clin Tech Eq Prac. 2004;3(1): 45-56.

29. Asplin KE, Sillence MN, Pollitt CC, McGowan CM. Induction of laminitis by prolonged hyperinsulinaemia in clinically normal ponies. Vet J. 2007;174(3):530-535

30. Nourian AR, Asplin KE, McGowan CM, Sillence MN, Pollitt CC. Equine laminitis: ultrastructural lesions detected in ponies following hyperinsulinaemia. Equine Vet J. 2009;41(7):671-677.

31. Frank N, Tadros EM. Insulin dysregulation. Equine Vet J. 2014;46(1) 103-112.

32. Couetil L. Equine Cushing's disease: diagnosis and treatment. Paper presented at: 9th International Congress of World Equine Veterinary Association; January; 2006; Marrakesh, Morocco.

33. McFarlane D, Hale GM, Johnson EM, Maxwell LK. Fecal egg counts after anthelmintic administration to aged horses and horses with pituitary pars intermedia dysfunction. J Am Vet Med Assoc. 2010;236(3): 330-334.

34. Spelta CW, Axon JE. Case series of equine pituitary pars intermedia dysfunction in a tropical climate. Aust Vet J. 2012;90(11): $451-456$.

35. Beech J, Boston R, Lindborg S. Comparison of cortisol and acth responses after administration of thyrotropin releasing hormone in normal horses and those with pituitary pars intermedia dysfunction. J Vet Intern Med. 2011;25(6):1431-1438.

36. Alexander S, Irvine C, Livesey J, Donald R. Effect of isolation stress on concentrations of arginine vasopressin, $\alpha$-melanocyte-stimulating hormone and $\mathrm{ACTH}$ in the pituitary venous effluent of the normal horse. J Endocrinol. 1988;116(3):325-334.

37. Fazio E, Medica P, Aronica V, Grasso L, Ferlazzo A. Circulating $\beta$-endorphin, adrenocorticotrophic hormone and cortisol levels of stallions before and after short road transport: stress effect of different distances. Acta Vet Scand. 2008;50:6.

38. Cavallone E, di Giancamillo M, Secchiero B, Belloli A, Pravettoni D, Rimoldi EM. Variations of serum cortisol in argentine horses subjected to ship transport and adaptation stress. J Equine Vet Sci. 2002;22(12): 541-545.

39. Alexander S, Irvine C, Ellis M, Donald R. The effect of acute exercise on the secretion of corticotropin-releasing factor, arginine vasopressin, and adrenocorticotropin as measured in pituitary venous blood from the horse. Endocrinology. 1991;128(1):65-72.

40. Donaldson M, McFarlane D, Jorgensen A, Beech J. Correlation between plasma-melanocyte-stimulating hormone concentration and body mass index in healthy horses. Am J Vet Res. 2004;65(11): 1469-1473.

41. Funk RA, Stewart AJ, Wooldridge AA, et al. Seasonal changes in plasma adrenocorticotropic hormone and $\alpha$-melanocyte-stimulating hormone in response to thyrotropin-releasing hormone in normal, aged horses. J Vet Intern Med. 2011;25(3):579-585. 
42. Donaldson MT, McDonnell SM, Schanbacher BJ, Lamb SV, McFarlane D, Beech J. Variation in plasma adrenocorticotropic hormone concentration and dexamethasone suppression test results with season, age, and sex in healthy ponies and horses. J Vet Intern Med. 2005;19(2):217-222.

43. Frank N, Elliott SB, Chameroy KA, Tóth F, Chumbler NS, McClamroch R. Association of season and pasture grazing with blood hormone and metabolite concentrations in horses with presumed pituitary pars intermedia dysfunction. $J$ Vet Intern Med. 2010;24(5): 1167-1175.

44. McFarlane D, Paradis M, Zimmel D, et al. The effect of geographic location, breed, and pituitary dysfunction on seasonal adrenocorticotropin and $\alpha$-melanocyte-stimulating hormone plasma concentrations in horses. J Vet Intern Med. 2011;25:872-881.

45. Rendle DI, Litchfield E, Heller J, Hughes KJ. Investigation of rhythms of secretion and repeatability of plasma adrenocorticotropic hormone concentrations in healthy horses and horses with pituitary pars intermedia dysfunction. Equine Vet J. 2014;46(1):113-117.

46. Copas VEN, Durham AE. Circannual variation in plasma adrenocorticotropic hormone concentrations in the UK in normal horses and ponies, and those with pituitary pars intermedia dysfunction. Equine Vet J. 2012;44(4):440-443.

47. Rendle DI, Duz M, Beech J, Parkin T, Durham AE. Investigation of single and paired measurements of adrenocorticotropic hormone for the diagnosis of pituitary pars intermedia dysfunction in horses. $J$ Vet Intern Med. 2015;29(1):355-361.

48. Diez de Castro E, Lopez I, Cortes B, Pineda C, Garfiab B, AguileraTejero E. Influence of feeding status, time of the day, and season on baseline adrenocorticotropic hormone and the response to thyrotropin releasing hormone-stimulation test in healthy horses. Domest Anim Endocrinol. 2014;48:77-83.

49. Rendle DI, Litchfield E, Gough S, Cowling A, Hughes KJ. The effects of sample handling and $n$-phenylmaleimide on concentration of adrenocorticotrophic hormone in equine plasma. Equine Vet J. Epub 2014 July 1.

50. Goodale L, Frank N, Hermida P, D'Oench S. Evaluation of a thyrotropin-releasing hormone solution stored at room temperature for pituitary pars intermedia dysfunction testing in horses. Am J Vet Res. 2015;76(5):437-444.

51. Karikoski N, Horn I, McGowan T, McGowan C. The prevalence of endocrinopathic laminitis among horses presented for laminitis at a first-opinion/referral equine hospital. Domest Anim Endocrinol. 2011; 41(3):111-117.

52. Bailey SR, Menzies-Gow NJ, Harris PA, et al. Effect of dietary fructans and dexamethasone administration on the insulin response of ponies predisposed to laminitis. J Am Vet Med Assoc. 2007;231(9):1365-1373.

53. Carter RA, Treiber KH, Geor RJ, Douglass L, Harris PA. Prediction of incipient pasture-associated laminitis from hyperinsulinaemia, hyperleptinaemia and generalised and localised obesity in a cohort of ponies. Equine Vet J. 2009;41(2):171-178.
54. Mastro LM, Adams AA, Urschel KL. Pituitary pars intermedia dysfunction does not necessarily impair insulin sensitivity in old horses. Domest Anim Endocrinol. 2015;50:14-25.

55. Vick M, Adams A, Murphy B, et al. Relationships among inflammatory cytokines, obesity, and insulin sensitivity in the horse. J Anim Sci. 2007;85(5):1144-1155.

56. Malinowski K, Betros C, Flora L, Kearns C, McKeever K. Effect of training on age-related changes in plasma insulin and glucose. Equine Vet J. 2002;34(S34):147-153.

57. Frank N. Equine metabolic syndrome. Vet Clin North Am Equine Pract. 2011;27(1):73-92.

58. Schuver A, Frank N, Chameroy KA. Use of an oral sugar test to assess insulin sensitivity in healthy and insulin-resistant horses. $J$ Vet Intern Med. 2010;24(3):780.

59. Durham AE. Equine metabolic syndrome: measuring and monitoring response to treatment and management. University of Melbourne Equine Centre Annual Conference; Werribe, Victoria; 2013.

60. Frank N. Equine metabolic syndrome. In: Smith BP, editor. Large Animal Internal Medicine. 5th ed. St Louis, MO: Elsevier Health Sciences; 2014:1240-1243.

61. Cordero M, McFarlane D, Breshears MA, Miller LM, Miller MA, Duckett WM. The effect of season on the histologic and histomorphometric appearance of the equine pituitary gland. $J$ Equine Vet Sci. 2012;32(2):75-79.

62. Frank N, Geor RJ, Bailey SR, Durham AE, Johnson PJ. Equine metabolic syndrome. J Vet Intern Med. 2010;24(3):467-475.

63. Geor RJ, Harris P. Dietary management of obesity and insulin resistance: countering risk for laminitis. Vet Clin North Am: Equine Pract. 2009;25(1):51-65.

64. Adams AA, Siard MH, Reedy SE, Little JP, Grubbs S, Little MP. Does equine pituitary pars intermedia dysfunction (PPID) affect immune responses to vaccination? Paper presented at: Dorothy Russell Havemeyer Foundation Equine Geriatric Workshop II 3rd Equine Endocrine Summit; 2014; Middleburg, VA.

65. McFarlane D. Immunosenescence in horses. Paper presented at: Proceedings of the 59th Annual Convention of the American Association of Equine Practitioners; 2013; Nashville, TN.

66. Davis JL, Kirk LM, Davidson GS, Papich MG. Effects of compounding and storage conditions on stability of pergolide mesylate. J Am Vet Med Assoc. 2009;234(3):385-389.

67. Peters D, Erfle J, Slobojan G. Low-dose pergolide mesylate treatment for equine hypophyseal adenomas (Cushing's syndrome). Paper presented at: 41st Annual Convention of the American Association of Equine Practioners; 1995; Lexington, KY.

68. Schott H, Coursen CL, Eberhart SW, et al. The Michigan Cushing's project. Paper presented at: Proceedings of the 47th Annual Convention of the American Association of Equine Practitioners; 2001; San Diego, CA.
Veterinary Medicine: Research and Reports

\section{Publish your work in this journal}

Veterinary Medicine: Research and Reports is an international, peer-reviewed, open access journal publishing original research, case reports, editorials, reviews and commentaries on all areas of veterinary medicine. The manuscript management system is completely online and includes a very quick and fair peer-review system.

\section{Dovepress}

Visit http://www.dovepress.com/testimonials.php to read real quotes from published authors. 